\title{
Intraocular lens design and the inhibition of epithelium
}

\author{
$S$ S SETTY AND $S$ P B PERCIVAL \\ From the Department of Ophthalmology, Scarborough District Hospital, Scarborough
}

SUMMARY Of 1170 eyes implanted with posterior chamber lenses between 1981 and 1986 and having intact capsules at surgery, 1015 were examined two years after surgery, 741 were examined three years after surgery, and 308 were examined five years after surgery. At three years the capsulotomy rate for epithelium was $25 \%$ for 263 'lasergap' lenses, $2 \cdot 4 \%$ for 296 convex posterior lenses, $8 \cdot 2 \%$ for 73 planoposterior lenses with angulated loops. The highly significant difference for lasergap design, whether ridged, meniscus, or bossed, is of immediate interest to surgeons concerned with minimising the need for secondary capsulotomy. The two-year follow-up of soft hydrogel lenses suggested that these lenses also do not significantly retard the ingrowth of epithelium.

There are two main mechanisms whereby the posterior lens capsule may become opacified after extracapsular cataract surgery. ${ }^{1-3}$ One is the migration of epithelial cells on to the capsule, with proliferation into Elschnig's pearls (epithelium). The other involves lens epithelial metaplasia into myofibrolasts that induce fibrosis and contracture of the capsule (fibrosis).

Epithelium once within the visual axis will reduce visual acuity to less than $6 / 36$ within six months. Without a lens implant about $45 \%$ of patients require secondary capsulotomy within three years of surgery. ${ }^{+7}$ The incidence is reduced by the implantation of an intraocular lens, but by different degrees according to design.

Fibrosis reduces vision very slowly, ${ }^{3}$ being a smooth less opaque proliferation which may be enhanced by convex posterior lenses of polymethyl methacrylate. ${ }^{138}$ Fibrosis also occurs more rapidly in association with inflammatory syndromes. ${ }^{8}$ Without lens implantation its incidence as a cause of secondary capsulotomy is approximately $2 \%$.

This paper considers solely epithelium, and the influence of implant design on the need for secondary capsulotomy.

Correspondence to Dr S P B Percival, Scarborough Hospital, Scarborough, North Yorkshire YO12 6QL

\section{Materials and methods}

All patients who had undergone extracapsular cataract extraction with an intact capsule at surgery and insertion of a posterior chamber implant between 1981 and 1986 were called for examination two, three, and five years after surgery. Perforating injuries and secondary implantations were excluded. The age range at surgery was 29 to 94 (mean 74) years. Of the 958 patients (1170 eyes) called for review two years after surgery, 18 had moved from the district, 122 had died, and 818 were examined. Of these 197 had undergone bilateral surgery, making the total number of eyes examined 1015. By three years the death toll had risen to $17 \%, 17$ patients (19 eyes) were untraceable, and 619 patients (741 eyes) were examined. Four hundred and fifty-eight operations were eligible for five-year follow-up, having been performed prior to 1984 . Of these, 128 were lost because the patient had died $(28 \%), 22$ eyes (21 patients) were untraceable, and 308 eyes were examined.

The lenses examined at two years were grouped (a) as 182 planoposterior convex anterior (CA) lenses; $(b)$ as 431 reversed optic or convex posterior $(\mathrm{CP})$ lenses; $(c)$ as 320 lasergap lenses; and $(d)$ as 82 biconvex hydrogel lenses made of polyhydroxyethyl methacrylate ( $38 \%$ water), the design of which has 
Table 1 Styles of lenses analysed: (a) convex anterior (CA), (b) convex posterior (CP), (c) laser gap, (d) biconvex hydrogel

\begin{tabular}{|c|c|c|c|c|c|c|c|}
\hline \multirow{2}{*}{\multicolumn{2}{|c|}{ Manufacturer }} & \multirow[t]{2}{*}{ Code and style } & \multirow[t]{2}{*}{ Placement } & \multirow[t]{2}{*}{ Haptics } & \multicolumn{3}{|c|}{ Number examined } \\
\hline & & & & & $2 y r$ & $3 y r$ & $5 y r$ \\
\hline \multirow[t]{2}{*}{ (a) } & Rayner & 487 Boberg-Ans & Iridocapsular & Solid PMMA & 99 & 96 & 79 \\
\hline & Iolab & 103Q Sinskey & Ciliary Sulcus & Polyprop. loops & 83 & 73 & 68 \\
\hline & Rayner & 850 Pearce & $\begin{array}{l}\text { Sulcus 1981-3 } \\
\quad \text { Capsule 1984-6 }\end{array}$ & Polyprop. loops & 4.31 & 296 & 161 \\
\hline \multirow[t]{6}{*}{ (c) } & Cilco & JFILRU Jaffe & Capsule & PMMA loops & 1.56 & 115 & 0 \\
\hline & Prec. Cosmet & $8661 \mathrm{Kratz}$ & Capsule & PMMA loops & 44 & 43 & () \\
\hline & Prec. Cosmet & 9310 & Capsule & PMMA loops & 56 & 42 & 0 \\
\hline & Rayner & 860 & Capsule & Polyprop. loops & 35 & 34 & () \\
\hline & Iolab & $707 \mathrm{G}$ & Capsule & Polyprop. loops & 21 & 21 & () \\
\hline & Pharmacia & Laser spacer & Capsule & Polyprop. loops & 8 & 8 & 0 \\
\hline (d) & Alcon & PC12 Barrett & Capsule & Solid hydrogel & 82 & 13 & 0 \\
\hline
\end{tabular}

PMMA = polymethyl methacrylate.

Table 2 Incidence of capsulotomy for epithelium among laser gap lenses at three years' follow-up

\begin{tabular}{|c|c|c|c|c|c|}
\hline Manufacturer & & Laser space design & $\begin{array}{l}\text { Number of } \\
\text { eyes }\end{array}$ & $\begin{array}{l}\text { Number of } \\
\text { capsulotomies }\end{array}$ & $(\%)$ \\
\hline Cilco & JFI & Circumferential ridge & 115 & 36 & 31 \\
\hline Prec. Cosmet & 8661 & Four bosses & 43 & 9 & 21 \\
\hline Prec. Cosmet & 9310 & Circumferential ridge & 42 & 13 & 31 \\
\hline Rayner & 860 & Meniscus & 34 & 5 & 15 \\
\hline Iolab & $707 \mathrm{G}$ & Circumferential ridge & 21 & 3 & 14 \\
\hline Pharmacia & & Circumferential ridge & 8 & () & () \\
\hline
\end{tabular}

Table 3 Comparative need for capsulotomy for epithelium among eyes examined

\begin{tabular}{|c|c|c|c|c|c|c|c|c|c|}
\hline & \multicolumn{9}{|c|}{ Examination } \\
\hline & \multicolumn{3}{|c|}{ At 2 years } & \multicolumn{3}{|c|}{ At 3 years } & \multicolumn{3}{|c|}{ At 5 years } \\
\hline & Eyes & Caps. & $\%$ & Eyes & Caps. & $\%$ & Eyes & Caps. & $\%$ \\
\hline Boberg Ans CA & 99 & 2 & $2 \cdot 0$ & 96 & 4 & $4 \cdot 2$ & 79 & 8 & $10 \cdot 1$ \\
\hline Sinskey CA & 83 & 4 & $4 \cdot 8$ & 73 & 6 & $8 \cdot 2$ & 68 & 9 & $13 \cdot 2$ \\
\hline Pearce CP & 431 & 4 & 0.9 & 296 & 7 & $2 \cdot 4$ & 161 & 9 & $5 \cdot 6$ \\
\hline Laser gap & 320 & 52 & $16 \cdot 2$ & 263 & 66 & $25 \cdot 0$ & 0 & & \\
\hline Hydrogel CP & 82 & 14 & $17 \cdot 1$ & 13 & 4 & 3()$\cdot 8$ & 0 & & \\
\hline No implant & 88 & 20 & $22 \cdot 7$ & 80 & 34 & $42 \cdot 5$ & 67 & 31 & $46 \cdot 2$ \\
\hline
\end{tabular}

been well documented elsewhere." Details of the styles, placements, and follow-up are shown in Table 1. All flexible loops were angulated forwards. The solid hydrogel haptics were also angulated forwards.

The criteria for a need for capsulotomy were significant capsular opacification reducing the visual acuity to less than $6 / 12$ or a visual acuity of $6 / 9$ or $6 / 12$ but associated with symptoms from mild opacification. Whenever a capsulotomy had been performed, a note had been recorded specifically on whether the reason for capsulotomy was ingrowth of epithelium or fibrosis of the lens capsule. All eyes were examined as to whether visual loss was occurring due to capsular opacification or whether secondary capsul- otomy had been performed in the past. In this study only the findings of those eyes requiring or having required capsulotomy for epithelium were recorded.

\section{Results}

The need for capsulotomy before three years had passed among laser gap lenses is shown in Table 2. These were lenses designed to provide a space behind the lens optic for later YAG laser treatment, and the laser space design is also indicated in the table. Although variation occurred among different styles, the numbers were too few to be significant, and for further comparison these eyes were grouped together as 'lasergap' lenses. 


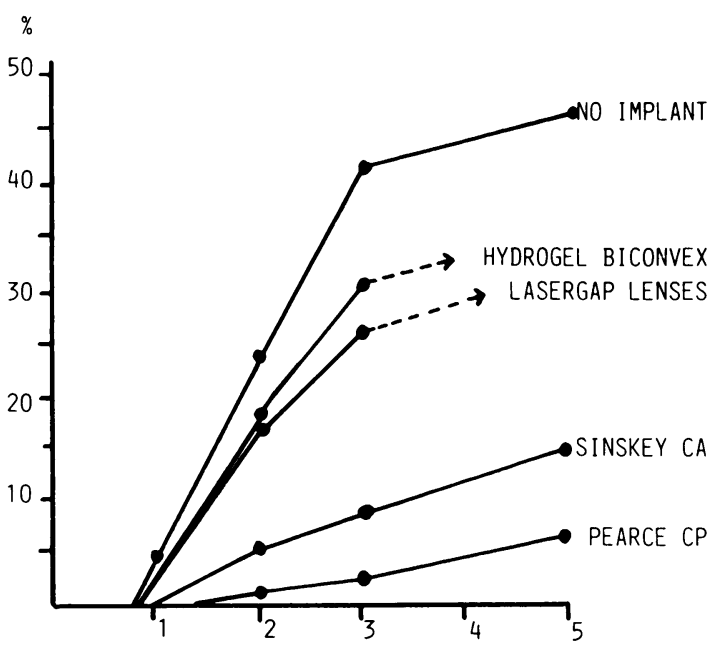

FOLLOW-UP (YEARS)

Fig. 1 Incidence of capsulotomy for epithelium

The comparative incidence of capsulotomy for epithelium among eyes that had intact capsules at surgery when examined two, three, and five years later is shown in Table 3. Eighty-eight eyes from an earlier period' operated on without lens implantation and examined similarly have been included for comparison. Fig. 1 compares the incidences in graphic form.

Age was not found to be a factor in determining the incidence of capsulotomy (the mean age was 73 years), and there were no other clinical factors relevant to ingrowth of epithelium apart from implant style, which was highly significant. Just two years after surgery $16 \%$ of the 320 lasergap lenses were associated with capsulotomy compared with $1.6 \%$ of the other 613 polymethyl methacrylate lenses. Convex posterior lenses had the smallest incidence of capsulotomy of $1 \%$ at two years, rising to $5.6 \%$ at five years. The hydrogel lenses although biconvex, had an incidence of capsulotomy of $17 \%$ two years after surgery.

\section{Discussion}

The capsulotomy rate for about three years of followup has been reported as $5 \%,{ }^{11} 8 \%,{ }^{11} 9 \%,{ }^{72} 15 \%,{ }^{11}$ $18 \%,{ }^{21+} 24 \%,{ }^{5}$ and $29 \%$." The discrepancies may be related to any of a number of factors:

(1) Age of the population sampled. It has been suggested that a disproportionate number of younger adults will increase the mean incidence of epithelialisation. ${ }^{2}$ However, in the present study at three years, although $22 \%$ of eyes requiring capsulotomy for epithelium were in patients under the age of 65 , it was also found that $26 \%$ of eyes were in patients over the age of 80 at the time of extracapsular cataract extraction.

(2) Structure of the study. An incidence prepared for a mean follow-up period will be skewed downwards by inclusion of numbers with insufficient follow-up, since epithelialisation of the lens capsule is rare before 15 months. We attach great importance in reporting only on patients who have passed the two, three, and five year stage after surgery.

(3) Accounting for all patients undergoing surgery. Many authors report the number of eyes showing opacification per eyes operated on without specifying the number unavailable because of death of being too infirm to attend or possible removal to a different district for capsulotomy. This method may indicate the likelihood of a patient's requiring a second operation in a particular surgeon's practice, but it does not reflect the true incidence to be expected for a given implant.

(4) Style of lens. CP lenses ${ }^{2+15}$ and angulated haptics" are associated with less opacification than those which are planoposterior or uniplanar. Our results support this finding, with an incidence of epithelium at three years of only $2.4 \%$ for CP lenses compared with $8.2 \%$ for the Sinskey CA lenses. Our results do not support the suggestion first by Hoffer ${ }^{16}$ and later by $\mathrm{Jaffe}^{17}$ that a circumferential ridge on the posterior aspect of the lens will significantly retard the ingrowth of epithelium.

It should be remembered, however, that tight contact of the posterior capsule against $\mathrm{CP}$ lenses may favour the development of fibrosis, ${ }^{1.3}$ especially in the presence of inflammatory syndromes which may result from sulcus placement or association with glaucoma surgery. ${ }^{x}$ In a separate study we found that 49 of the eyes examined at three years had been associated with the glaucoma triple procedure or past glaucoma surgery. Ten of these had required capsulotomy for fibrosis (eight out of $28 \mathrm{CP}$ lenses). With these 49 glaucomatous eyes excluded the incidence of capsulotomy for fibrosis at three years was found to be 10 of $268 \mathrm{CP}$ lenses, two of $160 \mathrm{CA}$ lenses, and four of 251 lasergap lenses. After exclusion of the Boberg Ans lenses, which are now obsolete, and the glaucomatous eyes, this gave a combined incidence for capsulotomy at three years of $6 \cdot 3 \%$ (17 out of 268) for CP lenses, $8.7 \%$ (six out of 69 ) for Sinskey CA lenses, and $26 \cdot 7 \%$ ( 67 out of 251 ) for laser gap lenses.

(5) Lens position. Capsule fixation may have a lower incidence of opacification than sulcus fixation, "' but we do not consider epithelium to be seriously influenced by position. We believe that the optic design is more relevant.

The conclusions to be drawn from this study are, first, that surgeons who continue with laser gap 
lenses, even if capsule fixated, subject themselves to an unnecessary work load in caring for capsular opacification. Secondly, CP lenses markedly inhibit epithelial ingrowth, so that biconvex or planoconvex designs should be encouraged. Thirdly, hydrogel lenses behave differently. Although these soft implants may have theoretical advantages over hard lenses in more closely mimicking the properties of living tissue and being hydrophylic, they do not significantly retard the ingrowth of epithelium even when initially positioned with a tight contact against the posterior lens capsule.

\section{References}

1 Cobo LM, Oshsawa E, Chandler D, Arguello R, George G. Pathogenesis of capsular opacification after extracapsular cataract extraction. Ophthalmology 1984: 91: 857-63.

2 Sterling S, Wood TO. Effect of intraocular lens convexity on posterior capsule opacification. J Cataract Refract Surg 1986; 12: $655-7$.

3 Santos BA, Pastora R. Del Monte MA. O'Donnell FE. Comparative study of the effects of optic design on lens epithelium in vitro. J Cataract Refract Surg 1987; 13: 127-30.

4 Kratz RP. 200() cases of phakoemulsification. Current concepts in cataract surgery. St Louis: Mosby, 1976: 121-3.

5 Sinskey RM. Cain W Jr. The posterior capsule and phakoemulsification. J Am Intraocul Implant Soc 1978: 4: 206-7.

6 Wilhelmus KR. Emery JM. Posterior capsule opacification following phakoemulsification. Ophthalmic Surg 1980; 11: $264-7$.
7 Percival SPB. Long term complications from extracapsular cataract surgery. Trans Ophthalmol Soc UK 1985; 104: 915-8.

8 Percival SPB, Setty SS. Analysis of the need for secondary capsulotomy during a five year follow up. J Cataract Refract Surg 1988: 14: 379-82.

9 Barrett GD, Constable IJ, Stewart AD. Clinical results of hydrogel lens implantation. J Cataract Refract Surg 1986; 12 : 623-31.

$10 \mathrm{Nishi} \mathrm{O}$. Incidence of posterior capsule opacification in eyes with and without posterior chamber lenses. J Cataract Refract Surg 1986: 12: 519-22.

11 Downing JE. Long term discission rate after placing posterior chamber lenses with the convex surface posterior. J Cataract Refract Surg 1986: 12: 651-4.

12 Leisegang TJ, Bourne WM, Ilstrup DM. Secondary surgical and YAG laser discissions. Am J Ophthalmol 1985; 100: 510-9.

13 Harris WS. An approach to intraocular lens implantation. In: Rosen ES, Haining WM. Arnott EJ, eds. Intraocular lens implantation. St Louis: Mosby, 1984: 495-9.

14 Lindstrom RL, Harris WS. Management of posterior capsule following posterior chamber lens implantation. $J$ Am Intraocul Implant Soc 1980; 6: 255-8.

15 Sellman TR, Lindstrom RL. Effect of a plano convex posterior chamber lens on capsular opacification from Elschnig pearl formation. J Cataract Refract Surg 1988; 14: 68-72.

16 Hoffer KJ. Five years' experience with the ridged laser lens implant. In: Emery JM, Jacobson AC, eds. Current concepts in cataract surgery (eighth congress). New York: Appleton-Century Crofts, 1983: chapter 96: 296-9.

17 Jaffe NS. Current and future concepts of the design of the intraocular lens. Trans Ophthalmol Soc UK 1985; 104: 703-14.

Accepted for publication 26 June 1989. 